\title{
Influence of Capacitive Effects on Transformer Windings
}

\author{
Mathurin Gogom*, Rodolphe Gomba, Desire Lilonga-Boyenga \\ Polytechnical Superior National School, Marien Ngouabi University, Brazzaville, Congo \\ Email: *mathuringogom@gmail.com
}

How to cite this paper: Gogom, M., Gomba, R. and Lilonga-Boyenga, D. (2021) Influence of Capacitive Effects on Transformer Windings. Energy and Power Engineering, 13, 67-80.

https://doi.org/10.4236/epe.2021.132005

Received: June 4, 2020

Accepted: January 31, 2021

Published: February 3, 2021

Copyright (c) 2021 by author(s) and Scientific Research Publishing Inc. This work is licensed under the Creative Commons Attribution International License (CC BY 4.0).

http://creativecommons.org/licenses/by/4.0/

\begin{abstract}
For years, capacitive effects have been the subject of research [1] and [2]. The capacitive effects are discrete capacitors that appear between active conductors of power lines and between them with the ground plane, generating capacitive reactive power to the network [1] and [2]. Indeed, it must be noted that these effects affect the windings of the transformer when the coupling is in star or triangle. This study is conducted to show that capacitive effects affect transformer windings differently when coupling is in stars or triangles. The results obtained are interesting and can be exploited in electrical transmission networks to ensure a long lifespan of transformers.
\end{abstract}

\section{Keywords}

Capacitive Effects, Discrete Capacitors, Geometry of Conductors, Transformers Windings

\section{Introduction}

The transport of electrical energy between production and consumption centres, often characterized by long distances, poses many problems, among other things, joule losses and voltage drops [3] [4] [5] [7] and [8]. To this end, several works have been carried out, including the optimization of joule losses and voltage drops through traditional or advanced compensation of reactive power [3] [4] [5] [6] and [7]. However, work on the impact of capacitive effects is still very limited, requiring special attention.

Indeed, the reactive energy generated by discrete capacitors that are created between the different active conductors on the one hand, and between each active conductor with the plane of the ground on the other hand, varies according to the configuration (geometry) of the line. This generated reactive energy is distributed in half on each of the two ends of the line or cable [8] and [10]. 
When not consumed, this reactive energy generated becomes one of the causes of unwanted surges and therefore instability of the voltage of the network. These capacitive effects are very harmful when operating empty or low-load transportation system [11] [12] and [13]. These capacitive effects have a different impact on the transformer windings connected to the power transmission lines. This difference is due to the way the coils are paired.

The formation of these discrete capacitors reflects the capacitive effects on electrical lines and cables. The reactive power absorbed by the inductions of the lines or debited by the capacitors thus formed must obey the requirements of the networks, including the stability and reliability of the transport networks.

The interest of this work is to show how discrete capacitors affect transformers' coils differently because of their coupling. Therefore, special attention must be paid to the selection of the cutting of the windings of transformers operated in the transmission networks of electrical energy.

\section{Theoretical Study}

\subsection{Capacitors Illustrations}

A high voltage power line generates reactive energy because of the capacitors that form between the different conductors on the one hand, and between each conductor and the ground plane on the other hand, as illustrated in Figure 1 [3] and [4].

Indeed, the capacitor which forms between two conductors (1) and (2) for example, generates reactive power $Q_{12}$ to the network. Between the different line conductors, we have capacitors $C_{12}, C_{23}$ and $C_{13}$, and between each line conductor and the ground plane the capacitors $C_{10}, C_{20}$ and $C_{30}$.

\subsection{Reactive Power Generated}

The example of the plug circuit makes us understand that the capacitor sends its energy on the impedance which is in parallel with it; this allows us to deduce that among the various capacitors formed between the lines conductors, some generate undesirable reactive energy on the transformers windings at the level of the departure and arrival stations when the line is operating at empty or at low load.

The power generated by the capacitor formed between the two conductors ( $i$ ) and $(j)$ as shown in Figure 2, is found in half on each end of the section, that means $Q_{i j} / 2$ on each end [3] and [4].

\subsubsection{Triangle Transformer Coupling}

\section{1) Reactive powers generated}

It is established that the various capacitors formed between the line conductors appear as reactive energy sources as illustrated in Figure 3. They respectively supply impedances in parallel, in particular the transformer windings.

For a capacitor created between the active line conductor and the ground 


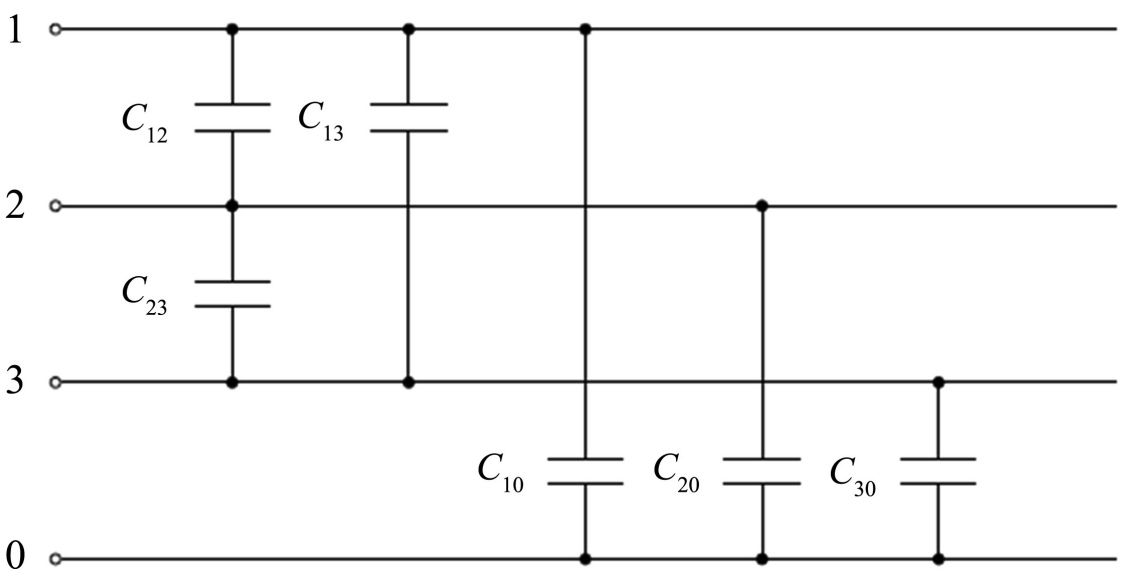

Figure 1. Capacities formed on a power line.

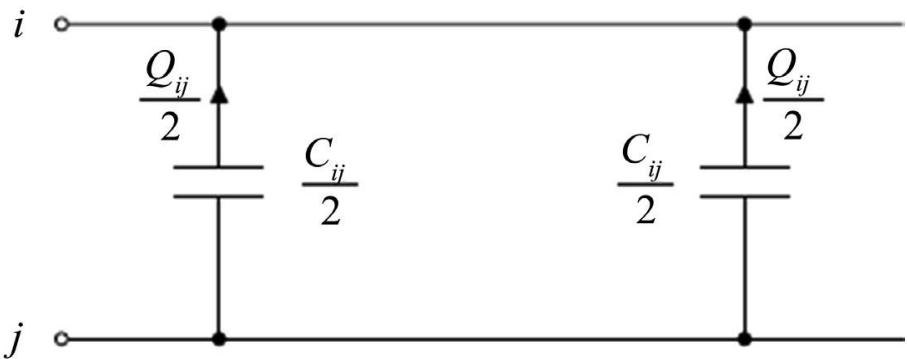

Figure 2. Distribution of reactive energy at the ends of the line.

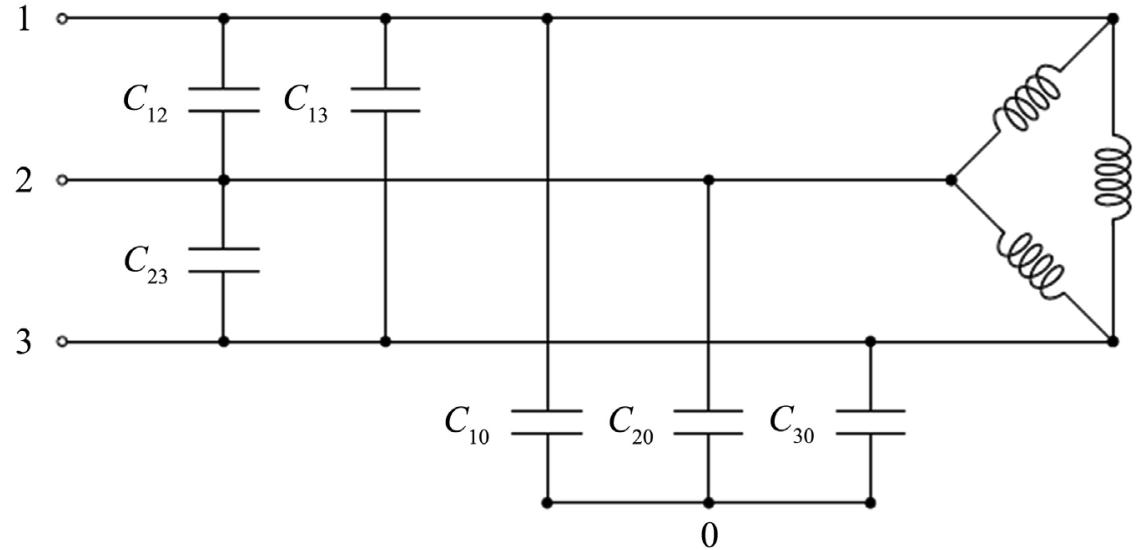

Figure 3. Case of coupling transformer's windings in triangle.

plane, the reactive power generated by these different capacitors is located between the phases and the ground plane. This reactive power is that which can be consumed by the equipment which are in parallel with them located at the entrance to the transformer station if these exist. The expression of this reactive power is given by the relation (1) below [1] [2]:

$$
Q_{i 0}=3 C_{i 0} \omega V_{i 0}^{2}
$$

where $V_{i 0}$ is the simple voltage of module $V_{i 0}=\frac{U_{12}}{\sqrt{3}}=\frac{U_{13}}{\sqrt{3}}=\frac{U_{23}}{\sqrt{3}}$ et $i=1,2$ 
and 3;

For the capacitors formed between the guard cables and the ground plane, it can be said that all the energy is earthed, because the two plates constituting this capacitor are earthed; regarding the capacitor created between an active conductor and the guard wire, we find ourselves in the case of a capacitor armature which is connected to earth. Here, we join the previous case where the power generated by the capacitor is sent to earth.

In the case of the capacitor formed between two guard cables, the two armatures of the capacitor thus formed are connected to the ground through pylons. The reactive energy generated is well flowed to the earth;

Regarding the capacitors formed between active conductors, the reactive powers generated by the three capacitors created between the two active conductors of the line are such that:

$$
Q_{12}=C_{12} \omega\left(U_{12}\right)^{2}, Q_{13}=C_{13} \omega\left(U_{13}\right)^{2} \text { et } Q_{23}=C_{23} \omega\left(U_{23}\right)^{2}
$$

At the start station, this reactive power generated by the capacitors of the line is consumed by the secondary winding of the transformer while at the arrival station; this reactive power is consumed by the primary winding of the transformer at this station. Then we can write [1] [2]:

$$
\begin{gathered}
Q_{12}=\frac{U_{12}^{2}}{L_{12} \omega} \text { then } L_{12}=\frac{U_{12}^{2}}{Q_{12} \omega^{2}} \\
Q_{13}=\frac{U_{13}^{2}}{L_{13} \omega} \text { then } L_{13}=\frac{U_{13}^{2}}{Q_{13} \omega^{2}} \\
Q_{23}=\frac{U_{23}^{2}}{L_{23} \omega} \text { then } L_{23}=\frac{U_{23}^{2}}{Q_{23} \omega^{2}}
\end{gathered}
$$

\section{2) Equivalent capacities}

For the purposes of modeling a power line in $\mathrm{T}$ or in $\pi$, the value of the capacity $\mathrm{C}$ to be taken into account per phase is the capacity resulting from the transformation of Figure 4.

The triangle formed by nodes 1, 2 and 3 can be reduced to the star shape by the triangle-star transformation. The point " $n$ " is at the same potential as the earth, the values of $C_{1 n}, C_{2 n}$ and $C_{3 n}$ are given by [8]: (Figure 5)

$$
\begin{gathered}
C_{1 n}=C_{12}+C_{13}+\frac{C_{12} C_{13}}{C_{23}} \\
C_{2 n}=C_{12}+C_{23}+\frac{C_{12} C_{23}}{C_{13}} \\
C_{3 n}=C_{13}+C_{23}+\frac{C_{13} C_{23}}{C_{12}}
\end{gathered}
$$

We arrive at the final equivalent diagram of Figure 6 of which $C_{\dot{e} q 1}, C_{\dot{e} q 2}$ and $C_{\dot{e} q 3}$ are given by the expressions below:

$$
C_{e q 1}=C_{1 n}+C_{10}
$$




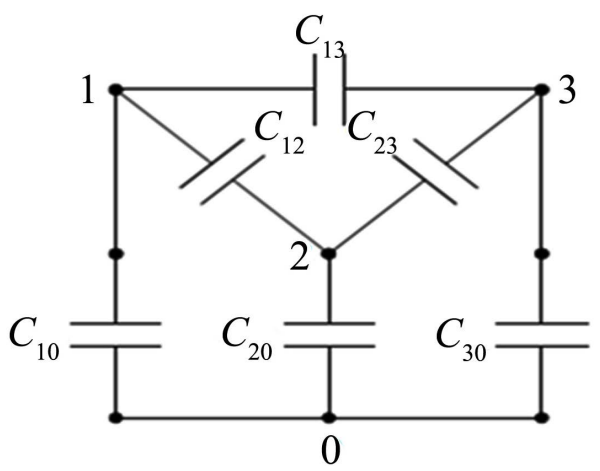

Figure 4. Simplified diagram of a dull simple line.

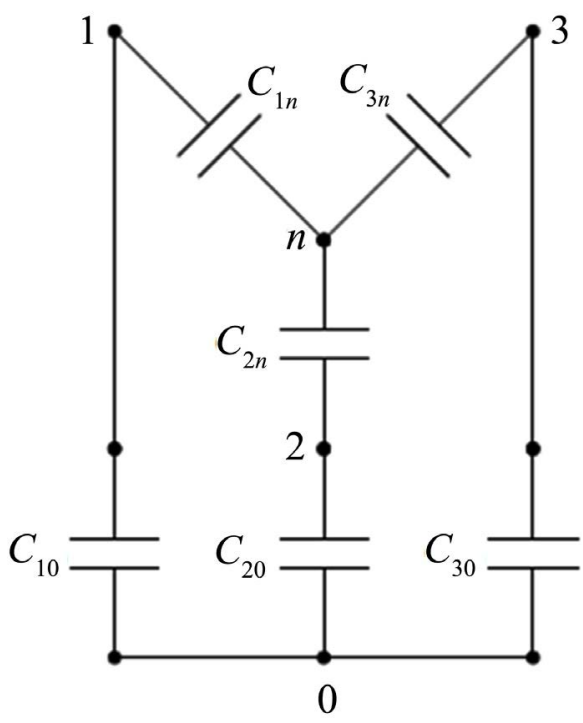

Figure 5. Equivalent diagram in star.

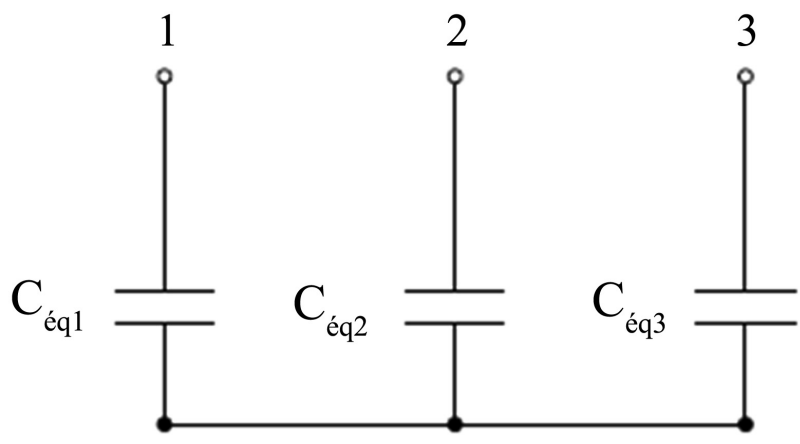

Figure 6. Final equivalent diagram.

$$
\begin{aligned}
& C_{\dot{e} q 2}=C_{2 n}+C_{20} \\
& C_{\dot{e} q 3}=C_{3 n}+C_{30}
\end{aligned}
$$

\subsubsection{Star Transformer Coupling}

1) Reactive power generated

As in the previous case, the different capacitors formed act in the same way. 
They feed the impedances which are parallel to them (Figure 7).

For a capacitor created between the line active conductor and the ground, the reactive power generated by these different capacitors is located between the phases and the ground. This reactive power is that consumed by half the transformers windings of the upstream and downstream stations of the line. It is given by the relation:

$$
Q_{i 0}=3 C_{i 0} \omega V_{i 0}^{2}
$$

where $V_{i 0}$ is the simple voltage for which the module is given by $V_{i 0}=\frac{U_{12}}{\sqrt{3}}=\frac{U_{13}}{\sqrt{3}}=\frac{U_{23}}{\sqrt{3}}, i=1,2$ and 3;

As for the capacitors formed between the guard cables and the ground, all of the reactive energy is earthed; Regarding the capacitor created between an active conductor and the guard wire, all reactive energy is discharged to the earth; In the case of the capacitor formed between two guard cables, the reactive energy generated is well drained to the earth; As regards the capacitors formed between two active conductors, the reactive powers generated by each capacitor are such that:

$$
Q_{12}=C_{12} \omega\left(U_{12}\right)^{2}, Q_{13}=C_{13} \omega\left(U_{13}\right)^{2}, Q_{23}=C_{23} \omega\left(U_{23}\right)^{2}
$$

At the start station, half of this reactive power generated by the capacitors formed between line active conductors is consumed by the two secondary windings of the transformer; and at the arrival station, the other half of this reactive power is consumed by the two primary windings of the transformer at this station. Each winding consumes:

$$
\begin{aligned}
& Q_{1}=L_{1} \omega I_{1}^{2}=\frac{V_{1}^{2}}{L_{1} \omega} \\
& Q_{2}=L_{2} \omega I_{2}^{2}=\frac{V_{2}^{2}}{L_{2} \omega} \\
& Q_{12}=Q_{1}+Q_{2}
\end{aligned}
$$

We deduce successively:

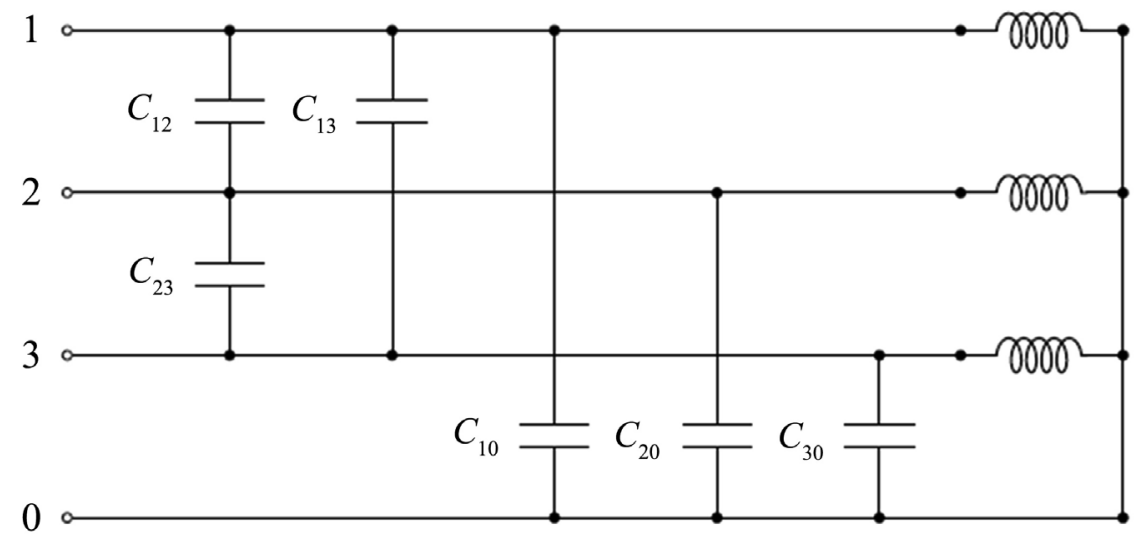

Figure 7. Line supplying the windings of a star-mounted transformer. 


$$
\begin{aligned}
& Q_{12}=\frac{V_{1}^{2}}{L_{1} \omega}+\frac{V_{2}^{2}}{L_{2} \omega} \\
& Q_{13}=\frac{V_{1}^{2}}{L_{1} \omega}+\frac{V_{3}^{2}}{L_{3} \omega} \\
& Q_{23}=\frac{V_{2}^{2}}{L_{2} \omega}+\frac{V_{3}^{2}}{L_{3} \omega}
\end{aligned}
$$

\section{2) Equivalent capacities}

For modeling purposes of a power line in $\mathrm{T}$ or $\pi$, the value of the capacitance $\mathrm{C}$ to be taken into account per phase is the capacitance resulting from the transformation of Figure 8 below.

For modeling purposes of a power line in $\mathrm{T}$ or $\pi$, the value of the capacitance $\mathrm{C}$ to be taken into account per phase is the capacitance resulting from the transformation of Figure 8 below.

The triangle formed by nodes 1,2 and 3 can be reduced to a star shape by the triangle-star transformation. The point " $n$ " is at the same potential as the earth, the values of $C_{1 n}, C_{2 n}$ and $C_{3 n}$ are given by: (Figure 9)

$$
\begin{gathered}
C_{1 n}=C_{12}+C_{13}+\frac{C_{12} C_{13}}{C_{23}} \\
C_{2 n}=C_{12}+C_{23}+\frac{C_{12} C_{23}}{C_{13}} \\
C_{3 n}=C_{13}+C_{23}+\frac{C_{13} C_{23}}{C_{12}}
\end{gathered}
$$

We arrive at the following final equivalent diagram: (Figure 10)

Under the balanced three-phase regime hypothesis, point $n$ is at the same potential as earth, thus:

$$
\begin{aligned}
& C_{\dot{e} q 1}=C_{1 n}+C_{10} \\
& C_{\dot{e} q 2}=C_{2 n}+C_{20} \\
& C_{\dot{e} q 3}=C_{3 n}+C_{30}
\end{aligned}
$$

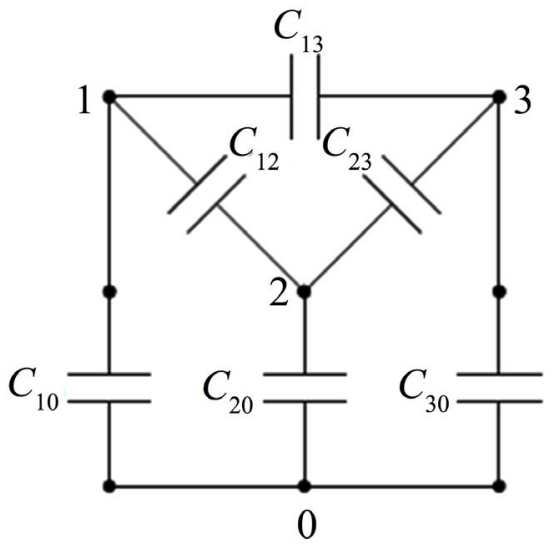

Figure 8. Simplified diagram of a dull single line. 


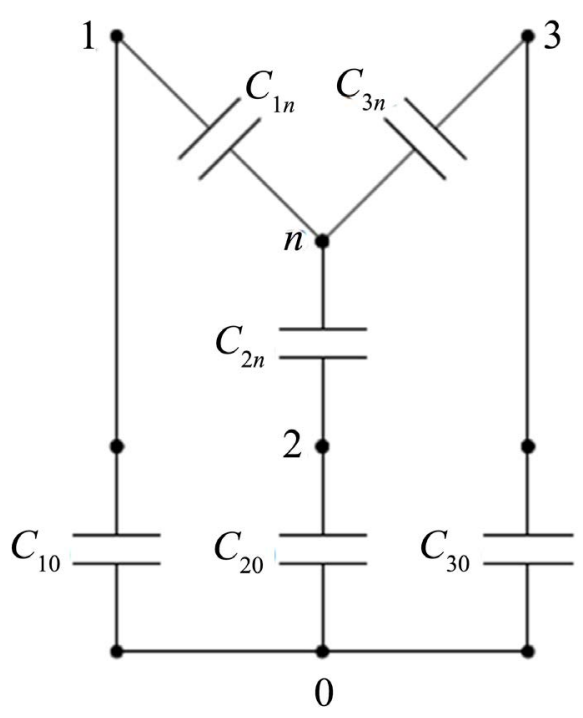

Figure 9. Equivalent diagram in star.

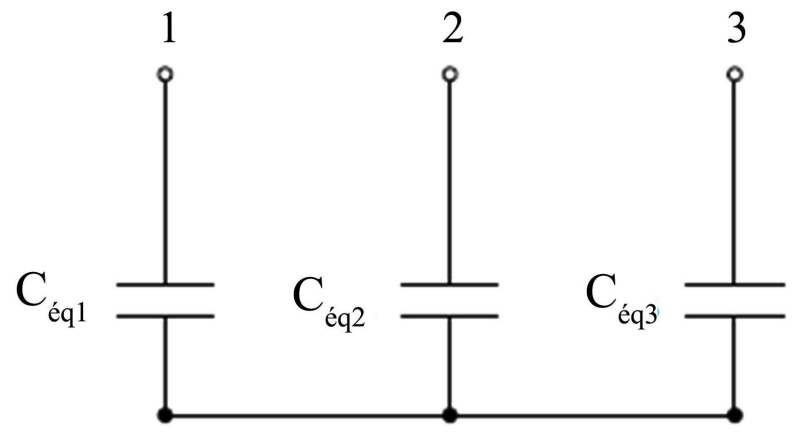

Figure 10. Final equivalent diagram.

\subsection{Capacitor Capacity}

It is a question of giving the expressions of the capacitors capacities formed between the line active conductors on the one hand, and between line active conductor with the ground plane on the other hand by taking into account the geometry of the lines. The capacity of a capacitor formed between two active conductors is given by [11] [12] [13]:

$$
C_{i j}=\frac{\pi \varepsilon_{0}}{\log \left[\frac{\frac{D_{i j}}{2}+\sqrt{\frac{D_{i j}^{2}}{4}+r^{2}}}{r}\right]}
$$

However, that of a capacitor formed between the active conductor and the ground plane is given by [11] [12] [13]:

$$
C_{i 0}=\frac{2 \pi \varepsilon_{0}}{\log \left[\frac{h_{i 0}+\sqrt{h_{i 0}^{2}+r^{2}}}{r}\right]}
$$


where:

$D_{i j}$, the distance between two active conductors; $r$, conductor radius; $\varepsilon_{0}$, absolute permittivity in a vacuum $\left(\varepsilon_{0}=8.854 \times 10^{-12} \mathrm{~F} / \mathrm{m}\right)$ and $h_{i 0}$, the distance between the active conductor and the ground plane.

\section{Determination of Reactive Capacities and Powers}

\subsection{Reactive Capacities and Powers}

We use formulas (2), (12), (13), (20) and (21) to calculate the capacities and the reactive powers generated $C_{i j}, C_{i 0}, Q_{i j}$ and $Q_{i 0}$ as a function of the voltage level and the geometry of the single term line conductors; the distance between two active conductors, the radius of the conductor and the distance between the active conductor on the ground plane. The results obtained are reported in Table 1 and Table 2 below.

We note, from the results recorded in Table 1 , that the capacities $C_{i j}$ and $C_{i 0}$ are not the same; they vary according to the geometry of the line conductors. The reactive powers $Q_{i j}$ and $Q_{i 0}$ generated vary in the same way. It should also be noted that the reactive power generated by the capacitor formed between the active conductor and the ground plane decreases as the height between them increases. Similarly, that generated by the capacitors formed between active conductors decreases when the distance between them increases.

\subsection{Equivalent Capacities and Reactive powers}

The formulas (6), (7), (8), (9), (10), (11) and (12) enabled us to calculate the equivalent capacities values of the capacitors thus formed for each voltage level. However, formulas (1) and (12) allowed us to calculate the reactive powers generated per phase. The results obtained are presented in Table 3.

For each given voltage level, the equivalent capacities $C_{e q i}$ and the reactive powers generated $Q_{i}$ differ from one geometry of the line conductors to another. Likewise, the equivalent capacities and the reactive powers generated differ from one phase to another. With regard to the results in Table 4, we note that the windings of the transformers consume different reactive powers.

Table 1. Capacitance values of capacitors formed.

\begin{tabular}{ccccccc}
\hline & \multicolumn{3}{c}{$110 \mathrm{KV}$} & \multicolumn{3}{c}{$220 \mathrm{KV}$} \\
\cline { 2 - 7 } Capacitance & Nappe & $\begin{array}{c}\text { Equilateral } \\
\text { Triangle }\end{array}$ & $\begin{array}{c}\text { Isocel } \\
\text { Triangle }\end{array}$ & Nappe & $\begin{array}{c}\text { Equilateral } \\
\text { Triangle }\end{array}$ & $\begin{array}{c}\text { Isocel } \\
\text { Triangle }\end{array}$ \\
\hline$C_{12}\left(10^{-12} \mathrm{~F} / \mathrm{m}\right)$ & 10.144 & 10.144 & 10.144 & 9.6136 & 9.6136 & 9.6136 \\
$C_{13}\left(10^{-12} \mathrm{~F} / \mathrm{m}\right)$ & 9.1405 & 10.144 & 9.616 & 8.7076 & 9.6136 & 9.1382 \\
$C_{23}\left(10^{-12} \mathrm{~F} / \mathrm{m}\right)$ & 10.144 & 10.144 & 10.144 & 9.6136 & 9.6136 & 9.6136 \\
$C_{10}\left(10^{-12} \mathrm{~F} / \mathrm{m}\right)$ & 15.198 & 15.198 & 14.876 & 15.251 & 15.251 & 14.799 \\
$C_{20}\left(10^{-12} \mathrm{~F} / \mathrm{m}\right)$ & 15.198 & 14.647 & 15.198 & 15.251 & 14.501 & 15.251 \\
$C_{30}\left(10^{-12} \mathrm{~F} / \mathrm{m}\right)$ & 15.198 & 15.198 & 15.198 & 15.251 & 15.251 & 15.251 \\
\hline
\end{tabular}


Table 2. Reactive powers values generated.

\begin{tabular}{lcccccc}
\hline & \multicolumn{3}{c}{$110 \mathrm{KV}$} & & \multicolumn{3}{c}{$220 \mathrm{KV}$} \\
\cline { 2 - 7 } Reactive powers & Nappe & $\begin{array}{c}\text { Equilateral } \\
\text { Triangle }\end{array}$ & $\begin{array}{c}\text { Isocel } \\
\text { Triangle }\end{array}$ & Nappe & $\begin{array}{c}\text { Equilateral } \\
\text { Triangle }\end{array}$ & Isocel Triangle \\
\hline$Q_{12}(\mathrm{KVAR} / \mathrm{Km})$ & 38.541 & 38.541 & 38.541 & 146.104 & 146.104 & 146.104 \\
$Q_{13}(\mathrm{KVAR} / \mathrm{Km})$ & 34.728 & 38.541 & 36.535 & 132.336 & 146.104 & 138.879 \\
$Q_{23}(\mathrm{KVAR} / \mathrm{Km})$ & 38.541 & 38.541 & 38.541 & 146.104 & 146.104 & 146.104 \\
$Q_{10}(\mathrm{KVAR} / \mathrm{Km})$ & 57.745 & 57.745 & 56.522 & 231.777 & 231.777 & 224.923 \\
$Q_{20}(\mathrm{KVAR} / \mathrm{Km})$ & 57.745 & 55.651 & 57.745 & 231.777 & 220.376 & 231.777 \\
$Q_{30}(\mathrm{KVAR} / \mathrm{Km})$ & 57.745 & 57.745 & 57.745 & 231.777 & 231.777 & 231.777 \\
\hline
\end{tabular}

Table 3. Equivalent capacitance values of the capacitors formed.

\begin{tabular}{ccccccc}
\hline \multirow{2}{*}{$\begin{array}{c}\text { Equivalent } \\
\text { capacitance }\end{array}$} & Nappe & $\begin{array}{c}\text { Equilateral } \\
\text { Triangle }\end{array}$ & $\begin{array}{c}\text { Isocel } \\
\text { Triangle }\end{array}$ & Nappe & $\begin{array}{c}\text { Equilateral } \\
\text { Triangle }\end{array}$ & $\begin{array}{c}\text { Isocel } \\
\text { Triangle }\end{array}$ \\
\cline { 2 - 7 } & 43.6235 & 45.63039 & 44.2529 & 42.2799 & 44.0918 & 41.8289 \\
$C_{\text {eq.1 }}\left(10^{-12} \mathrm{~F} / \mathrm{m}\right)$ & 45.6304 & 45.07924 & 46.1872 & 45.0920 & 43.3416 & 44.5919 \\
$C_{\text {eq. }}\left(10^{-12} \mathrm{~F} / \mathrm{m}\right)$ & 43.6235 & 45.63039 & 44.5747 & 42.2799 & 44.0918 & 43.1410 \\
$C_{\text {eq.3 }}\left(10^{-12} \mathrm{~F} / \mathrm{m}\right)$ & & & & & & \\
\hline
\end{tabular}

Table 4. Reactive power values generated per phase.

\begin{tabular}{lcccccc}
\hline & \multicolumn{3}{c}{$110 \mathrm{KV}$} & \multicolumn{3}{c}{$220 \mathrm{KV}$} \\
\cline { 2 - 7 } Reactive power & Nappe & $\begin{array}{c}\text { Equilateral } \\
\text { Triangle }\end{array}$ & Isocel Triangle & Nappe & $\begin{array}{c}\text { Equilateral } \\
\text { Triangle }\end{array}$ & Isocel Triangle \\
\hline$Q_{1}(\mathrm{KVAR} / \mathrm{Km})$ & 165.7431 & 173.3681 & 168.1345 & 672.1592 & 670.0896 & 635.6988 \\
$Q_{2}(\mathrm{KVAR} / \mathrm{Km})$ & 173.3681 & 171.2741 & 175.4836 & 685.2900 & 658.6884 & 677.6898 \\
$Q_{3}(\mathrm{KVAR} / \mathrm{Km})$ & 165.7431 & 173.3681 & 169.3571 & 642.5528 & 670.0896 & 655.6396 \\
\hline
\end{tabular}

\subsection{Application to the Radial Network}

The influence of capacitive effects on the windings of the transformers located upstream and downstream of the lines is examined on the Liouesso-Ouesso network in the Sangha department of the Republic of Congo.

\subsubsection{Network Description}

The Liouesso-Ouesso electrical network is shown in Figure 11. These characteristics are summarized in Table 5.

\subsubsection{Network Modeling}

We possibly choose the basic voltage and power to transcribe the network parameters in pu [9]. So, $U_{B}=110 \mathrm{KV} ; S_{B}=100 \mathrm{MVA}$ and we deduce the basic impedance and admittance such as: $Z_{B}=\frac{U_{B}^{2}}{S_{B}}$ et $Y_{B}=\frac{S_{B}}{U_{B}^{2}}$. These parameters are presented in Table 6 and Table 7 below: 
Table 5. (a) Characteristics of the Liouesso-Ouesso network; (b) Continuation of the characteristics of the Liouesso-Ouesso network.

(a)

\begin{tabular}{rcccccccc}
\hline \multicolumn{4}{c}{ Alternators } & \multicolumn{5}{c}{ Transformation post of Liouesso } \\
\hline$U_{n}$ & $3 \times S_{n}$ & $\cos \varphi$ & $3 \times P_{n}$ & $U_{1 n}$ & $U_{2 n}$ & $S_{n}$ & $U_{n c c}$ & $P_{n c c}$ \\
$\mathrm{kV}$ & $\mathrm{MVA}$ & - & $\mathrm{MW}$ & $\mathrm{KV}$ & $\mathrm{KV}$ & $\mathrm{MVA}$ & $\%$ & $\mathrm{KW}$ \\
11 & 23.43 & 0.85 & 19.5 & 11 & 110 & 25 & 10.5 & 29 \\
\hline
\end{tabular}

(b)

\begin{tabular}{ccccccccc}
\hline & \multicolumn{2}{c}{ Ligne $110 \mathrm{kV}$} & & \multicolumn{5}{c}{ Transformation post of Ouesso } \\
\hline$L$ & $r_{0}$ & $x_{0}$ & $b_{0}$ & $U_{1 n}$ & $U_{2 n}$ & $S_{n}$ & $U_{n c c}$ & $P_{n c c}$ \\
$\mathrm{Km}$ & $\Omega / \mathrm{Km}$ & $\Omega / \mathrm{Km}$ & $\Omega^{-1} / \mathrm{Km}$ & $\mathrm{KV}$ & $\mathrm{KV}$ & $\mathrm{MVA}$ & $\%$ & $\mathrm{KW}$ \\
120 & 0.17 & 0.39 & $2.95 .10^{-6}$ & 110 & 20 & 25 & 10.5 & 60 \\
\hline
\end{tabular}

Table 6. Longitudinal and transverse parameters of the line in pu.

\begin{tabular}{cccccc}
\hline No. & Sections & $R$ & $X$ & $G$ & $B$ \\
\hline 1 & $1-2$ & 0.025 & 0.27 & 0 & 0 \\
2 & $2-3$ & 0.17 & 0.4 & 0 & 0.43 \\
3 & $3-4$ & 0.012 & 0.09 & 0 & 0 \\
\hline
\end{tabular}

Table 7. Active and reactive powers at the nodes of the pu network.

\begin{tabular}{ccccc}
\hline No. & $P_{G}$ & $Q_{G}$ & $P_{C}$ & $Q_{C}$ \\
\hline 1 & 0 & 0 & & \\
2 & & 0 & 0 \\
3 & & 0 & 0 \\
4 & & 0 & 0 \\
\hline
\end{tabular}

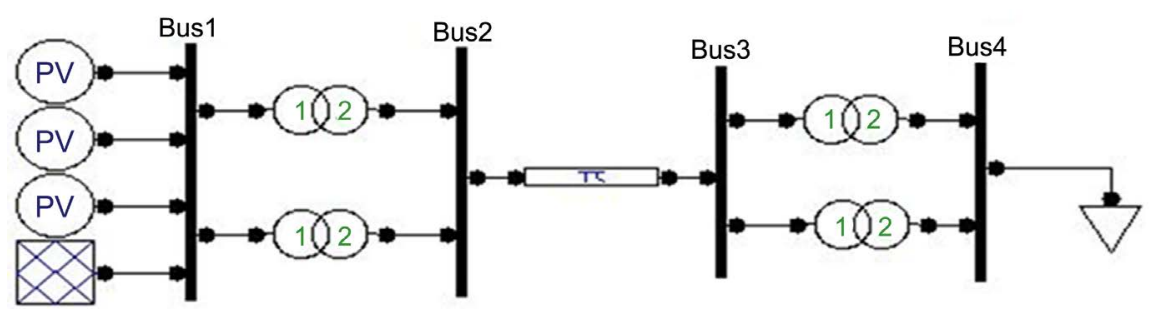

Figure 11. "Liouesso-Ouesso" Electrical network.

\subsubsection{Simulations, Results and Discussion}

The simulations are performed during no-load operation using the NewtonRaphson algorithm implemented in Matlab [9]. The results obtained are presented in the following Table 8.

From the results obtained, we can deduce the reactive powers generated by the capacitors formed between conductors using formula (2). These are presented in Table 9 below. At the end of these deductions, we will appreciate the influence 
of these capacitive effects on the transformers windings located upstream and downstream of the line.

\subsubsection{Inductance Deduction}

It is interesting to appreciate the inductances of the transformers windings which consume the reactive energy generated by the capacitors thus formed. The consumption of this energy varies according to the coupling of the windings.

1) Triangle coupling of windings

By applying formulas (3), (4) and (5), we obtain the results given in Table 10 below:

\section{2) Star coupling of windings}

Assuming that the system is symmetrical, solving Equations (17), (18) and (19) allows us to obtain the results recorded in Table 11 below:

The examination of the results recorded in Table 10 and Table 11 show that the geometry of the conductors in an equilateral triangle guarantees the symmetry of the three-phase system; however, the star coupling is more expensive, because the windings of this one can have a number of turns $\sqrt{3}$ times less than that of the transformer whose coupling of the windings is in triangle.

Table 8. Voltage modules and phases, then powers generated and consumed at the nodes in pu.

\begin{tabular}{ccccccc}
\hline No. & $V$ & $\varphi$ & $P_{G}$ & $Q_{G}$ & $P_{C}$ & $Q_{C}$ \\
\hline 1 & 1.0200 & 0 & 0.0195 & -0.5323 & & \\
2 & 1.1606 & -0.0157 & & & 0 & 0 \\
3 & 1.2688 & -0.0556 & & 0 & 0 \\
4 & 1.2688 & -0.0556 & & 0 & 0 \\
\hline
\end{tabular}

Table 9. Reactive powers generated during no-load operation.

\begin{tabular}{cccc}
\hline & \multicolumn{3}{c}{$110 \mathrm{KV}$} \\
\cline { 2 - 4 } Reactive powers & Nappe & Equilateral Triangle & Isocel Triangle \\
\hline$Q_{12}(\mathrm{MVAR})$ & 7.4454 & 7.4454 & 7.4454 \\
$Q_{13}(\mathrm{MVAR})$ & 6.7089 & 7.4454 & 7.0579 \\
$Q_{23}(\mathrm{MVAR})$ & 7.4454 & 7.4454 & 7.4454 \\
\hline
\end{tabular}

Table 10. Inductances values of the windings transformer.

\begin{tabular}{cccc}
\hline \multirow{2}{*}{ Inductances } & \multicolumn{3}{c}{$110 \mathrm{KV}$} \\
\cline { 2 - 4 } & Nappe & Equilateral Triangle & Isocel Triangle \\
\hline$L_{12}(\mathrm{H})$ & 8.3321 & 8.3321 & 8.3321 \\
$L_{23}(\mathrm{H})$ & 8.3321 & 8.3321 & 8.3321 \\
$L_{13}(\mathrm{H})$ & 9.2468 & 8.3321 & 8.7895 \\
\hline
\end{tabular}


Table 11. Inductances values of the transformer's windings.

\begin{tabular}{cccc}
\hline & \multicolumn{3}{c}{$110 \mathrm{KV}$} \\
\cline { 2 - 4 } inductances & Nappe & Equilateral Triangle & Isocel Triangle \\
\cline { 2 - 4 } & 2.777 & 2.777 & 2.777 \\
$L_{1}(\mathrm{H})$ & 3.082 & 2.777 & 2.929 \\
$L_{2}(\mathrm{H})$ & 2.777 & 2.777 & 2.777 \\
\hline
\end{tabular}

\section{Conclusions}

In our study, we first modeled the line by essentially representing discrete capacitors between active conductors on the one hand, and between active conductors and the ground on the other. Then we calculated the capabilities of discrete capacitors. Similarly, equivalent capacities were deducted. In the end, the examination of the influence of capacitive effects on transformer coils was done on the existing radial power grid in the Republic of Congo. The results show that:

- Discrete capacitors generate reactive energies that vary depending on the geometry of line conductors;

- Capacitive effects affect transformer coils differently depending on whether the coupling is in a triangle or a star;

- For triangle coupling, the coiling of the transformer's coil consumes all of the energy generated;

- For star coupling, the energy generated is consumed by the two coils of the transformer's coils.

In short, the design of line conductors in equilateral triangle is ideal compared to other models when it comes to ensuring the symmetry of the three-phase system. However, star coupling is more advantageous than triangle coupling, as the number of coils spins is reduced by $\sqrt{3}$ times and the coil induction will be 3 times smaller, and therefore the star coupling guarantees a long life of the transformer compared to the one whose coupling is in a triangle.

\section{Conflicts of Interest}

The authors declare no conflicts of interest regarding the publication of this paper.

\section{References}

[1] Lyazid, H. and Khodir, H. (2015) Calcul des Paramètres et Caractéristiques des Lignes Électriques Triphasées. Mémoire de Master 2 Génie Électrique, Université Abderrahmane Mira, Béjaïa.

[2] Wildi, T. and Sibille, G. (2005) Electrotechnique. 4e Édition, Presses de l'Université Laval, Québec.

[3] Abba Labane, H. and Omboua, A. (2016) Capacitive Dividers on the High Voltage Lines. International Journal of Engineering and Advanced Research Technol$o g y, 2,26-32$.

[4] Abba Labane, H., Omboua, A. and Lilonga-Boyenga, D. (2017) Capacitive Effects 
on Electrical Lines and Cables. International Journal of Engineering Science Invention, 6, 25-32.

[5] Sayah, A. (2017) Analyse des Terminaisons d'Eau. Thèse de l'Université des Sciences et de la Technologie d'Oran Mohamed Boudiaf, Bir El Djir.

[6] Omboua, A. (2017) Soutirage de l'Énergie le Long des Lignes à Haute Tension: Technologie Profitable Pour les Pays en Développement. International Journal of Innovation and Applied Studies, 20, 349-357.

[7] Lagonotte, P. (2004) Les Lignes et Des Câbles Électriques. In Chapitre 10 du Cours de Réseaux Électrique.

[8] Yalaoui, N. (2017) Calcul de la Matrice d'Impédances Linéiques du Système LigneCâble Avec la Méthode des Éléments Finis. Mémoire du Diplôme de Maitrise ès Sciences Appliquées Soutenu en 2017.

[9] Gogom, M., Mimiesse, M., Nguimbi, G. and Lilonga-Boyenga, D. (2018) Improving Availability of Transit Capacity by the Hybrid Optimization Method. Journal of Scientific and Engineering Research, 5, 1-13.

[10] Dan Surianu, F. (2009) Determination of the Induced Voltages bby $220 \mathrm{kV}$ Electric Overhead Power Lines Working in Parallel and Narrow Routes. Measurements on the Ground and Mathematical Model. WSEAS Transactions on Power Systems, 4, 264-274.

[11] Souad, C. (2013) Réseaux Électriques en ses Divers Régimes Cours. Université Virtuelle de Tunis, Montplaisir, 23, 27.

[12] Boukhenoufa, F., Boukadoum, A., Leulmi, A., et al. (2012) Régulation Optimale de la Tension \& Compensation de la Puissance Réactive avec Contraintes de Sécurité, d'un Réseau Électrique, par la Méthode Hybride MPI \& AG, Université du 20 Août 1955 et Université Ferhat A., Skikda-Sétif (Algérie), 1-6.

[13] Betie, A. (2015) Impacts de la Qualité du Système d'Isolation sur la Condition et l'Efficacité des Transformateurs de Puissance. Thèse de l'Université du Québec, Quebec City. 